\title{
Quantifying hydrogen peroxide in iron-containing solutions using leuco crystal violet
}

\author{
Corey A. Cohn ${ }^{\text {a) }}$ \\ Department of Geosciences and Center for Environmental Molecular Science, Stony Brook University, \\ Stony Brook, New York 11794-2100 \\ Aimee Pak \\ Department of Chemistry and Center for Environmental Molecular Science, Stony Brook University, \\ Stony Brook, New York 11794-2100 \\ Daniel Strongin \\ Department of Chemistry, Beury Hall 201, 1901 North 13th Street, Temple University, Philadelphia, \\ Pennsylvania 19122 and Center for Environmental Molecular Science, Stony Brook University, Stony Brook, \\ New York 11794-2100
}

\section{Martin A. Schoonen}

Department of Geosciences and Center for Environmental Molecular Science, Stony Brook University, Stony Brook, New York 11794-2100

(Received 24 February 2005; accepted 26 April 2005; published 14 June 2005)

\begin{abstract}
Hydrogen peroxide is present in many natural waters and wastewaters. In the presence of $\mathrm{Fe}(\mathrm{II})$, this species decomposes to form hydroxyl radicals, that are extremely reactive. Hence, in the presence of $\mathrm{Fe}(\mathrm{II})$, hydrogen peroxide is difficult to detect because of its short lifetime. Here, we show an expanded use of a hydrogen peroxide quantification technique using leuco crystal violet (LCV) for solutions of varying $p \mathrm{H}$ and iron concentration. In the presence of the biocatalyst peroxidase, LCV is oxidized by hydrogen peroxide, forming a colored crystal violet ion $\left(\mathrm{CV}^{+}\right)$, which is stable for days. The LCV method uses standard equipment and allows for detection at the low microM concentration level. Results show strong $p \mathrm{H}$ dependence with maximum LCV oxidation at $p \mathrm{H}$ 4.23. By chelating dissolved Fe(II) with EDTA, hydrogen peroxide can be stabilized for analysis. Results are presented for hydrogen peroxide quantification in pyrite-water slurries. Pyrite-water slurries show surface area dependent generation of hydrogen peroxide only in the presence of EDTA, which chelates dissolved $\mathrm{Fe}$ (II). Given the stability of $\mathrm{CV}^{+}$, this method is particularly useful for field work that involves the detection of hydrogen peroxide. () 2005 American Institute of Physics. [DOI: $10.1063 / 1.1935449]$
\end{abstract}

\section{INTRODUCTION}

Hydrogen peroxide is an important reactant in natural aquatic systems, environmental remediation technologies, and in biological systems. Reactive oxygen species (ROS), which include hydrogen peroxide $\left(\mathrm{H}_{2} \mathrm{O}_{2}\right)$ and hydroxyl radicals $\left({ }^{\circ} \mathrm{OH}\right)$ occur in rain ${ }^{1,2}$ and surface waters. ${ }^{3,4}$ ROS play an important role in natural processes in aquatic systems, including, radiolysis, ${ }^{5,6}$ pyrite oxidation, ${ }^{7-9}$ and photochemical oxidation. ${ }^{10,11}$ Hydrogen peroxide also is intentionally added to wastewaters to promote in situ oxidation processes ${ }^{12,13}$ by leveraging the extreme reactivity of radicals toward organic pollutants. The generation of ${ }^{\circ} \mathrm{OH}$, via the decomposition of $\mathrm{H}_{2} \mathrm{O}_{2}$, degrades contaminants when methods involving microbiological degradation are ineffective. In organisms, including humans, ROS are produced during metabolic and immune system function. ${ }^{14}$ When ROS concentrations are above normal for prolonged periods of time, however, their presence can lead to oxidative stress. ${ }^{15}$ Oxidative stress is now recognized to be an important factor in the development or enhancement of many diseases. ${ }^{16}$

\footnotetext{
${ }^{\text {a) }}$ Author to whom correspondence should be addressed; electronic mail: ccohn@fulbrightweb.org
}

Among ROS, $\mathrm{H}_{2} \mathrm{O}_{2}$ is relatively stable,${ }^{17}$ in the presence of ferrous iron, $\mathrm{H}_{2} \mathrm{O}_{2}$ forms ${ }^{\circ} \mathrm{OH}$ via the Fenton reaction

$$
\mathrm{Fe}(\mathrm{II})+\mathrm{H}_{2} \mathrm{O}_{2} \rightarrow{ }^{\circ} \mathrm{OH}+\mathrm{OH}^{-}+\mathrm{Fe}(\mathrm{III}) .
$$

'OH is far more reactive than $\mathrm{H}_{2} \mathrm{O}_{2}$ and its reaction with aqueous species is diffusion limited. ${ }^{17}$ Therefore, $\mathrm{H}_{2} \mathrm{O}_{2}$, in the presence of $\mathrm{Fe}(\mathrm{II})$, represents great potential for reactivity.

In natural systems, ${ }^{\circ} \mathrm{OH}$ is a transient species and its steady-state concentration may only be in the $\mathrm{nM}$ range. The inherent reactivity of ${ }^{\circ} \mathrm{OH}$ precludes its detection via a direct measurement, and hence, methods generally rely on the detection of a stable reaction product resulting from the reaction of ${ }^{\circ} \mathrm{OH}$ and a target molecule. One strategy is to add a reactant as a target species that will oxidize in the presence of ${ }^{\circ} \mathrm{OH}$ and form a product that can be analyzed by UV-Vis spectroscopy ${ }^{2}$ or fluorescence. ${ }^{18}$ Verifying ${ }^{\circ} \mathrm{OH}$ involvement in oxidation of the target species is difficult. Addition of competing scavengers that react with ${ }^{\circ} \mathrm{OH}$ may inhibit oxidation of the target molecule; however, there is little conformity when using different scavengers and target molecules. ${ }^{19}$ Another strategy that is often employed is to "trap" the unpaired electron of the radical into a compound that is less 
reactive. By using electron paramagnetic resonance (EPR), the EPR intensity of the spin-trapped molecule can be directly related to the concentration of ${ }^{\circ} \mathrm{OH}$ in the solution. EPR spin-trapping is a very sensitive technique and has been widely used in chemistry, environmental sciences, and bio(medical) sciences; however, it does require a significant capital investment and spin-trapping cannot be conducted in the field. The spin-trapping technique has also been used for OH detection from aqueous mineral slurries, however reaction between $\mathrm{Fe}(\mathrm{III})$ and the spin-trap complicates interpretation of the data. ${ }^{20}$

Where detection of ${ }^{\circ} \mathrm{OH}$ is impracticable, identifying $\mathrm{H}_{2} \mathrm{O}_{2}$ may elucidate a reaction mechanism involving ${ }^{\circ} \mathrm{OH}$ formation. In iron-containing systems, both $\mathrm{H}_{2} \mathrm{O}_{2}$ and ${ }^{\circ} \mathrm{OH}$ are short-lived. However, chelation of iron [i.e., $\mathrm{Fe}(\mathrm{II})]$ avoids its interaction and decomposition of $\mathrm{H}_{2} \mathrm{O}_{2}$. Hence, we argue that hydrogen peroxide detected in iron-containing systems with an iron-chelator added is a proxy for the capacity of the system to generate ${ }^{\circ} \mathrm{OH}$ in the absence of an iron chelator. This strategy may prove useful as an alternative method for radical detection in natural systems.

Several methods are available for quantifying $\mathrm{H}_{2} \mathrm{O}_{2}$. UV-Vis absorbance $\left(240 \mathrm{~nm}, \epsilon=43.6 \mathrm{M}^{-1} \mathrm{~cm}^{-1}\right)^{21}$ is convenient for $\mathrm{H}_{2} \mathrm{O}_{2}$ solutions containing no other UV absorbing chromophores. Another spectrophotometric method uses copper(II) and 2,9-dimethyl-1,10-phenanthroline (DMP) for $\mu \mathrm{M} \mathrm{H}_{2} \mathrm{O}_{2}$ detection in wastewater. ${ }^{22}$ The colored complex does not change in the presence of humic acid; however, metal chelators affect the copper reactivity, complicating its use when iron chelation is necessary. For higher sensitivity detection, fluorometric techniques are available. The scopoletin/horseradish peroxidase method ${ }^{23}$ allows for detection of low $\mathrm{nM}$ concentrations, but the need for standard additions and quantification via a decrease in fluorescence prove to be time consuming. Another fluorometric technique involves the oxidation of non-fluorescent $2^{\prime}, 7^{\prime}$-dichlorofluorescin (DCFH) to fluorescent $2^{\prime}, 7^{\prime}$-dichlorofluorescein (DCF) in the presence of $\mathrm{H}_{2} \mathrm{O}_{2}$ and peroxidase. ${ }^{18}$ This technique is often used to detect the formation of $\mathrm{H}_{2} \mathrm{O}_{2}$ in cells. The technique makes use of the non-fluorescent (DCFHdiacetate) crossing of cell membranes, which is enzymatically deacetylated to non-fluorescent DCFH. Cellular production of $\mathrm{H}_{2} \mathrm{O}_{2}$ produces the fluorescent DCF. The deacetylation process can be achieved chemically, but $\mathrm{H}_{2} \mathrm{O}_{2}$ may be produced in the process ${ }^{24}$ resulting in background levels of $\mathrm{H}_{2} \mathrm{O}_{2}$. Another disadvantage for using the DCFH technique is the necessity for daily preparation of the DCFH reagent.

Here, we present results on an improved method for $\mathrm{H}_{2} \mathrm{O}_{2}$ detection in the $\mu \mathrm{M}$ to several hundred $\mathrm{nM}$ range, which has several advantages over preexisting methods. The leuco crystal violet (LCV) method ${ }^{25}$ involves oxidation of 4,4'4"'-methylidynetris ( $N, N$-dimethylaniline) $\quad\left(\mathrm{C}_{25} \mathrm{H}_{31} \mathrm{~N}_{3}\right)$ (LCV) in the presence of $\mathrm{H}_{2} \mathrm{O}_{2}$ and horseradish peroxidase (HRP) to form the crystal violet ion, $\mathrm{CV}^{+}$, which absorbs at $590 \mathrm{~nm} . \mathrm{CV}^{+}$remains stable for several days, which makes it possible to treat samples upon collection and perform the analysis at a later time. This is of value in field studies or shipboard analysis. ${ }^{26}$ Daily preparation of new reagents is not required and iron chelators do not affect the analysis.

In this report, the LCV method was employed for analysis of $\mathrm{H}_{2} \mathrm{O}_{2}$ in pyrite/aqueous slurries. Recently, ${ }^{9}$ pyrite $\left(\mathrm{FeS}_{2}\right)$, the most abundant metal sulfide mineral on Earth, has been shown to produce $\mathrm{H}_{2} \mathrm{O}_{2}$ in aqueous solutions. Several adjustments were made to the original LCV method so that it is now possible to determine $\mathrm{H}_{2} \mathrm{O}_{2}$ concentration in aqueous systems that contain iron-bearing minerals. Here, we determined effects of iron, $p \mathrm{H}$, and addition of EDTA. To verify that our technique was specific to the presence of $\mathrm{H}_{2} \mathrm{O}_{2}$, and that other species were not responsible for the oxidation of LCV in the presence of HRP, we carried out experiments in the presence of catalase. This enzyme selectively decomposes $\mathrm{H}_{2} \mathrm{O}_{2}$, and its addition to the solution prior to the addition of LCV and HRP eliminates the production of the $\mathrm{CV}^{+}$species.

\section{EXPERIMENT}

Leuco crystal violet (Spectrum) in the presence of the enzyme horseradish peroxidase (HRP) type II (Aldrich) forms a crystal violet cation, which has an absorbance maximum at $590 \mathrm{~nm}$. The absorbance of $\mathrm{CV}^{+}$was measured with a Hach DR4000 spectrometer interfaced with a laptop for data storage. Calibration curves were used to quantify the effects of $p \mathrm{H}$, iron (Fisher brand ferrous ammonium sulfate), and EDTA (Sigma) on the absorbance of $\mathrm{CV}^{+}$. Catalase (Sigma 40000 to 60000 units $/ \mathrm{mg}$ bovine liver) was used at a concentration around 100000 units per sample vial to verify the presence of $\mathrm{H}_{2} \mathrm{O}_{2}$. Pyrite (Wards brand from Huanzala, Peru) was crushed and sieved under an ambient atmosphere, acid washed $(0.1 \mathrm{M} \mathrm{HCl})$, and then thoroughly rinsed with $\mathrm{N}_{2}$-purged water (Easy Pure $18.3 \mathrm{M} \Omega \mathrm{cm}$, UVirradiated, and ultrafiltered) under $\mathrm{N}_{2}$ atmosphere to remove surface oxides. The acid-washed and cleaned pyrite was subsequently dried in a vacuum desiccator and stored under vacuum. The size fraction used in these experiments was between 10 and $90 \mu \mathrm{m}$ with a five point $\mathrm{N}_{2}$ adsorption BET surface area of roughly $1.25 \mathrm{~m}^{2} / \mathrm{g}$. This BET surface area is an approximation due to the inherent variations for low surface area measurements. ${ }^{27}$ Varying amounts of the pyrite were mixed with water in the absence or presence of 1-10 mM EDTA, then immediately filtered (Millipore $0.45 \mu \mathrm{m}$ ). Reagents [all stored at $4{ }^{\circ} \mathrm{C}$ and brought up to room temperature $\left(22 \pm 1{ }^{\circ} \mathrm{C}\right)$ before analyses] were added to the aqueous filtrate in the following order for a total volume of $2 \mathrm{ml}$ (also shown in Table I): $100 \mathrm{mM} \mathrm{KH}_{2} \mathrm{PO}_{4}$ (Aldrich) $p \mathrm{H} 4$ buffer, $41 \mu \mathrm{M}$ leuco crystal violet (dissolved with $\mathrm{HCl}$ ), and $4 \mathrm{mg} / 50 \mathrm{ml} \mathrm{HRP}$ [containing $1.5 \mathrm{mM}$ azide (Sigma) to prevent bacterial growth]. Samples were kept in the dark at room temperature $\left(22 \pm 1{ }^{\circ} \mathrm{C}\right)$ for $30 \mathrm{~min}$, upon which absorbance stabilized. Absorbance measurements were taken in $1 \mathrm{~cm}$ path-length cuvettes.

\section{RESULTS AND DISCUSSION}

The reagent preparations and volumes used are shown in Table I. It is useful to present our conditions in the context of prior LCV studies that were carried out by Zhang et al. ${ }^{26}$ 
TABLE I. LCV method details. ${ }^{\mathrm{a}}$

\begin{tabular}{|c|c|c|c|c|}
\hline Reagent & $\begin{array}{c}\text { Reagent } \\
\text { preparation }\end{array}$ & $\begin{array}{c}\text { Stock } \\
\text { concentration }\end{array}$ & $\begin{array}{l}\text { Volume } \\
\text { added } \\
(\mu 1)\end{array}$ & $\begin{array}{c}\text { Final } \\
\text { concentration }\end{array}$ \\
\hline Sample $^{\mathrm{b}}$ & $\cdots$ & $\cdots$ & 1700 & $\ldots$ \\
\hline $\begin{array}{c}\mathrm{KH}_{2} \mathrm{PO}_{4} \\
p \mathrm{H} \text { buffer }\end{array}$ & $\begin{array}{c}136.07 \mathrm{~g}+0.5 \mathrm{~L} \mathrm{H}_{2} \mathrm{O} \\
p \mathrm{H} \text { adjusted to } 4.2 \\
\text { with } \mathrm{H}_{3} \mathrm{PO}_{4}\end{array}$ & $1 \mathrm{M}$ & 200 & $100 \mathrm{mM}$ \\
\hline LCV & $\begin{array}{c}31 \mathrm{mg} \mathrm{LCV}+30 \mathrm{ml} \\
\mathrm{H}_{2} \mathrm{O}+19.2 \mathrm{ml} \text { of } 0.25 \\
\mathrm{~N} \mathrm{HCl}\end{array}$ & $1.65 \mathrm{mM}$ & 50 & $41 \mu \mathrm{M}$ \\
\hline HRP & $\begin{array}{l}4.0 \mathrm{mg} \mathrm{HRP}+50 \mathrm{ml} \\
\mathrm{H}_{2} \mathrm{O}+92 \mu \mathrm{l} \text { of } 1 \mathrm{M} \\
\text { sodium azide }\end{array}$ & $\begin{array}{c}0.08 \mathrm{mg} / \mathrm{ml}(14.4 \\
\text { units } / \mathrm{ml})\end{array}$ & 50 & $\begin{array}{c}1 \mu \mathrm{g}(0.18 \\
\text { units })\end{array}$ \\
\hline
\end{tabular}

${ }^{\mathrm{a}}$ Reagent preparations, concentrations, volume added, and final concentrations of the solutions added to a $4 \mathrm{ml}$ cuvette and kept in the dark before analysis. Reagents listed in order of addition. $\mathrm{H}_{2} \mathrm{O}_{2}$ calibration solutions were prepared by dilutions of a stock.

${ }^{\mathrm{b}}$ Samples containing pyrite were filtered.

Compared to the concentrations used by Zhang et al. for $p \mathrm{H}$ buffer, LCV, and HRP, we used 1.25 , 4, and 10 times those previously used, respectively, to increase (1) the buffer concentration, (2) the higher range of detection (more LCV), and (3) the reaction rate (more HRP). By increasing the concentration of our reagents, we were able to limit the volume of reagent addition so that a maximum volume would be available for the sample.

Figure 1 shows color development over time after the last reagent, HRP, is added to hydrogen peroxide and LCV. Absorbance levels plateau in 5-10 min and remain stable for several days. Zhang et $a l .^{26}$ waited 5 min before taking absorbance measurements; we waited $30 \mathrm{~min}$ just as a cautionary measure to ensure stability of the absorbance. The inset is a plot of wavelength scans showing maximum absorbance at $590 \mathrm{~nm}$ and an overlapping of scans after $2 \mathrm{~min}$. Absorbance measurements at $590 \mathrm{~nm}\left(A_{590}\right)$ were taken at $30 \mathrm{~min}$ for all other samples.

Addition of catalase is important for verifying the presence of $\mathrm{H}_{2} \mathrm{O}_{2}$, since other ROS or other reactions may also oxidize LCV. When catalase is added, no $\mathrm{H}_{2} \mathrm{O}_{2}$ is detected, which limits the possibility of false positives.

The LCV method is strongly affected by $p \mathrm{H}$, and Fig. 2 shows $A_{590}$ as a function of $p \mathrm{H}$. The optimal $p \mathrm{H}$ range is 3.6-4.2, where the peak intensity is the highest, but the intensity decreases by half as the $p \mathrm{H}$ increases to 4.37 (Fig. 2). Zhang et al $^{26}$ have shown a similar increase in absorbance up to around $p \mathrm{H} 4.5$. They report $\mathrm{CV}^{+}$precipitation at higher

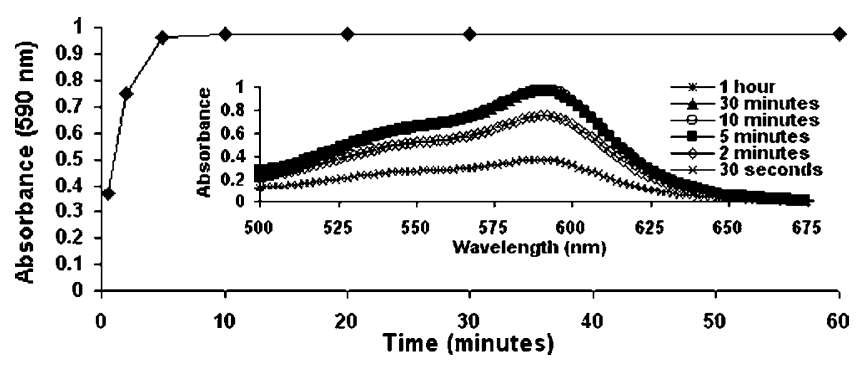

FIG. 1. Oxidation of LCV in the presence of $20 \mu \mathrm{M} \mathrm{H} \mathrm{H}_{2} \mathrm{O}_{2}$ and HRP as a function of time after addition of all reagents. Insert shows wavelength scans of the solutions showing maximum absorbance at $590 \mathrm{~nm}$. $p \mathrm{H}$, and here, the effect at $p \mathrm{H}$ greater than 4.5 is shown. Although $A_{590}$ is significantly reduced and the solutions are slightly turbid, calibration curves can still be produced and $\mathrm{H}_{2} \mathrm{O}_{2}$ quantified.

Figure 3 shows calibration curves made between $p \mathrm{H}$ 2.99 and 3.75 with $0-24 \mu \mathrm{M} \mathrm{H}_{2} \mathrm{O}_{2}$. At $p \mathrm{H}$ values of 3.20 and less, the method is not valid. In the $p \mathrm{H}$ range of 3.383.55 , the calibration curves are only useful at low $\mathrm{H}_{2} \mathrm{O}_{2}$ concentrations. At $p \mathrm{H} 3.64$ and 3.75, the curves are nearly linear. These results are consistent with those presented in Fig. 1, which showed the optimal $p \mathrm{H}$ range of around 3.6-4.2; here, the calibration curves are nearly linear at $p \mathrm{H} 3.64$ and 3.75 .

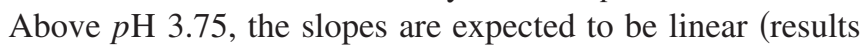
from higher- $p \mathrm{H}$ experiments are presented in the following). In separate experiments, which are not shown, calibration curves were extended into the $\mathrm{nM}$ region indicating a lower limit around $0.5 \mu \mathrm{M}$.

In the presence of $\mathrm{Fe}(\mathrm{II})$, EDTA is necessary for stabilizing $\mathrm{H}_{2} \mathrm{O}_{2}$. As solution $p \mathrm{H}$ is increased, EDTA is deprotonated, therefore having a higher capacity for chelation (the EDTA stock solution is $p \mathrm{H} \mathrm{8}$ ). In our experiments, $1 \mathrm{mM}$ EDTA with LCV reagents resulted in a $p \mathrm{H}$ around 3.67. At this $p \mathrm{H}$, calibration curves with EDTA are equivalent to those without EDTA. Figure 4 shows the effect of iron on $A_{590}$ at several $\mathrm{H}_{2} \mathrm{O}_{2}$ concentrations in the presence of $1 \mathrm{mM}$ EDTA. Even without $\mathrm{H}_{2} \mathrm{O}_{2}$, EDTA and iron oxidize $\mathrm{LCV}$ in the presence of HRP. This may be due to reaction of

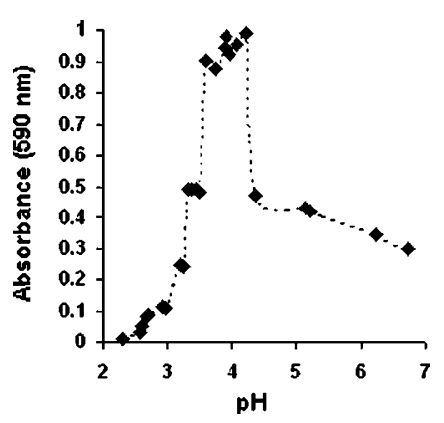

FIG. 2. Absorbance of the buffered LCV and HRP solution as a function of $p \mathrm{H}$ in the presence of $20 \mu \mathrm{M} \mathrm{H}_{2} \mathrm{O}_{2}$. 


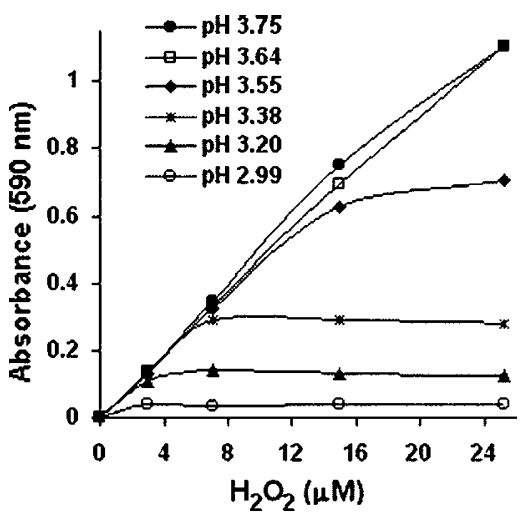

FIG. 3. Calibration curves as a function of $p \mathrm{H}$. $\mathrm{H}_{2} \mathrm{O}_{2}$ quantification using Beer's law is only applicable at $\mathrm{H}_{2} \mathrm{O}_{2} \lesssim 12 \mu \mathrm{M}$ for $p \mathrm{H}=3.55$ and $\lesssim 6 \mu \mathrm{M}$ for $p \mathrm{H}=3.38$.

LCV with either the electron-deficient chelated iron or ironEDTA complex. When ferrous iron is added at low concentrations $(0-15 \mu \mathrm{M})$ there is an increase in absorbance but the $A_{590}$ is not affected as the iron concentration is increased above $15 \mu \mathrm{M}$ iron. At low iron concentrations $(0-15 \mu \mathrm{M})$, the slopes of the calibration curves are nearly identical to those calculated from experiments without EDTA and iron. As iron is increased, $\mathrm{H}_{2} \mathrm{O}_{2}$ decreases. This experimental observation is due to a higher proportion of nonchelated iron, which reacts with $\mathrm{H}_{2} \mathrm{O}_{2}$. Although some of the $\mathrm{H}_{2} \mathrm{O}_{2}$ was decomposed in the presence of iron, linear calibration curves can still be generated. In these experiments, the concentration of EDTA is much greater than that for iron. EDTA chelation capacity decreases with decreasing $p \mathrm{H}$. The optimal $p \mathrm{H}$ for the LCV technique is around 4, which necessitates the addition of high concentrations of EDTA.

Figure 5 shows calibration curves with $10 \mathrm{mM}$ EDTA solutions at varying ferrous iron concentrations. The $p \mathrm{H}$ of these solutions is between 5.9 and 5.6. The $A_{590}$ does not vary by much as a function of $p \mathrm{H}$ in this region. Therefore, differences in the curves are due to iron. Compared to the high EDTA concentration, relatively low iron concentrations decompose $\mathrm{H}_{2} \mathrm{O}_{2}$. This is probably due to the low $p \mathrm{H}$ where EDTA has a lower chelation capacity. At higher iron concentrations, around $150-200 \mu \mathrm{M}$, only the higher $\mathrm{H}_{2} \mathrm{O}_{2}$ concentrations are detected. The $p \mathrm{H}$ for EDTA-containing solutions was buffered but the $p \mathrm{H}$ was not forced to the optimal $p \mathrm{H}$ of 4.23 because addition of highly acidic buffers alter EDTA chelation capacity and, in the field, it is easier to quantify $\mathrm{H}_{2} \mathrm{O}_{2}$ by using a $p \mathrm{H}$-specific calibration curve than trying to force the $p \mathrm{H}$ to 4.23 .

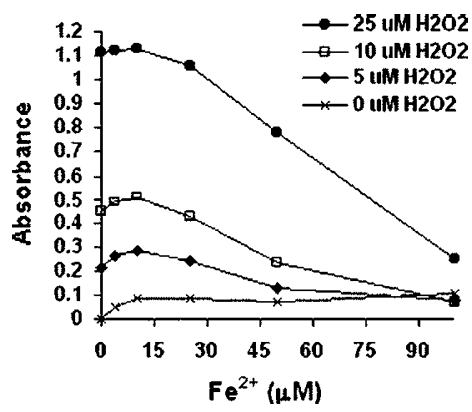

FIG. 4. Effect of dissolved ferrous iron on $A_{590}$ at several $\mathrm{H}_{2} \mathrm{O}_{2}$ concentrations (given in $\mu \mathrm{m}$ ) in the presence of $1 \mathrm{mM}$ EDTA at $p \mathrm{H}=3.67$.

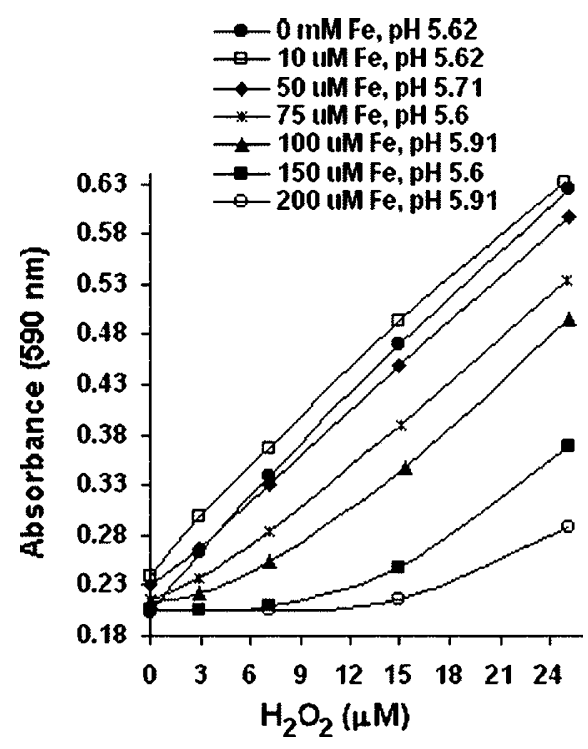

FIG. 5. Calibration curves as a function of ferrous iron (added as ferrous ammonium sulfate, given in $\mu \mathrm{m})$ in $10 \mathrm{mM}$ EDTA.

Using the DMP method ${ }^{28}$ and an ultrahigh vacuum mass spectroscopy technique, ${ }^{9}$ pyrite has recently been shown to produce $\mathrm{H}_{2} \mathrm{O}_{2}$. Here, we used the LCV method and employed EDTA to verify $\mathrm{H}_{2} \mathrm{O}_{2}$ at several particle loadings (Fig. 6). These results show a surface area dependence on $\mathrm{H}_{2} \mathrm{O}_{2}$ generation. The $\mathrm{H}_{2} \mathrm{O}_{2}$ concentrations reported here are about 200 times lower than those obtained previously (34 $\mu \mathrm{M}$ at a $4 \mathrm{~g} / \mathrm{L}$ loading). ${ }^{28}$ The higher readings in the prior study may have been due to the presence of dissolved $\mathrm{Fe}(\mathrm{II})$, which enhances $\mathrm{H}_{2} \mathrm{O}_{2}$ readings with the DMP method. The DMP method uses $\mathrm{Cu}$, so EDTA would interfere with the analysis. Hence the values reported in our earlier work based on the DMP method are overestimated.

Addition of catalase to the solution prior to the addition of LCV results in a colorless solution, suggesting that hydrogen peroxide was not present upon addition of LCV and HRP (Fig. 7). Catalase specifically reacts with $\mathrm{H}_{2} \mathrm{O}_{2}$, so that it will remove any $\mathrm{H}_{2} \mathrm{O}_{2}$ from the EDTA-treated solution. By performing two measurements, one with EDTA and one with EDTA plus catalase, we rule out false positives due to other reactions that could conceivably lead to the formation of $\mathrm{CV}^{+}$. Without EDTA, there is no LCV oxidation, since in this case ferrous iron, either on the pyrite surface or in solution, is not chelated and it can react with hydrogen peroxide to form ${ }^{\circ} \mathrm{OH}$. In a separate study, ${ }^{29}$ we have shown that without

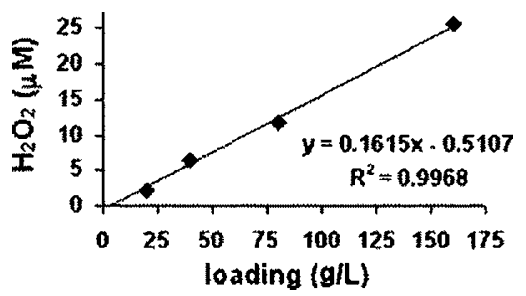

FIG. 6. Pyrite-generated $\mathrm{H}_{2} \mathrm{O}_{2}$ as a function of particle loadings. $1 \mathrm{mM}$ EDTA was used for the 20 and $40 \mathrm{~g} / \mathrm{L}$ loadings and $10 \mathrm{mM}$ EDTA was used for the 80 and $160 \mathrm{~g} / \mathrm{L}$ loadings. The EDTA solutions were quickly mixed with pyrite particles for about $3 \mathrm{~s}$ and filtered. LCV and HRP were then added to the filtrate. When catalase is added prior to $\mathrm{LCV}, \mathrm{H}_{2} \mathrm{O}_{2}$ is not detected. 


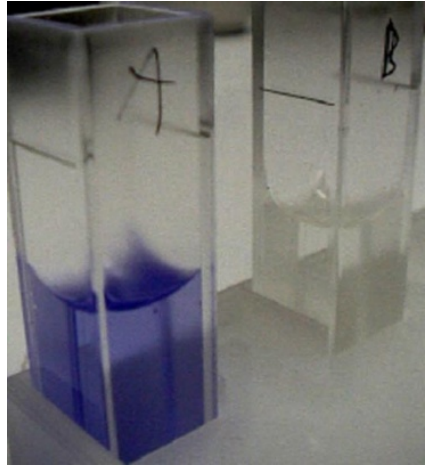

FIG. 7. (Color) Photograph of the cuvettes containing pyrite slurry filtrate and LCV reagents. Both contain $1 \mathrm{mM}$ EDTA. The left cuvette is purple due to $\mathrm{CV}^{+}$. On the right, catalase was added before addition of LCV. Catalase reacts rapidly with $\mathrm{H}_{2} \mathrm{O}_{2}$, preventing LCV oxidation and resulting in a colorless solution.

EDTA, pyrite readily degrades biomolecules including RNA, presumably due to hydroxyl radical generation from the reaction of ferrous iron with hydrogen peroxide. This study also showed that addition of EDTA protects the biomolecules, which are only degraded if ${ }^{\circ} \mathrm{OH}$ is formed.

For $\mathrm{H}_{2} \mathrm{O}_{2}$ detection in natural waters, the LCV technique may be one of the more suitable methods. It has already been shown that the method can be used for seawater analyses ${ }^{26}$ and here we show that it can be used for a $p \mathrm{H}$ range of around 3.5-6.0 and in the presence of EDTA. Compared to techniques involving fluorescence, where reagents are prepared on the day of analyses, our solutions of LCV and HRP remained stable for months at $4{ }^{\circ} \mathrm{C}$ in opaque centrifuge vials. The stability of $\mathrm{CV}^{+}$upon reaction of $\mathrm{H}_{2} \mathrm{O}_{2}$ and the LCV reagents makes it possible to quantify $\mathrm{H}_{2} \mathrm{O}_{2}$ several days after sampling. This can be exploited in field studies. For example, the LCV technique could be used to study the spatial and temporal distribution of $\mathrm{H}_{2} \mathrm{O}_{2}$ in hot spring waters in Yellowstone National Park. It has been shown that steady-state levels of photochemically produced $\mathrm{H}_{2} \mathrm{O}_{2}$ in the surface geothermal waters at Yellowstone National Park reach $200-600 \mathrm{nM}$ by late afternoon and decrease to less than $50 \mathrm{nM}$ during the night. ${ }^{30}$ With the LCV technique a large number of water samples can be collected and prepared for later analysis. Temperature is expected to affect the rate of the HRP-mediated reaction and it could possibly also affect the stability of the LCV or $\mathrm{CV}^{+}$. Probably the best strategy working with hydrothermal waters is to rapidly cool the sample down to a temperature between 20 and $30{ }^{\circ} \mathrm{C}$ before adding the reagents. Cooling the samples to much lower temperature may impede the enzyme reaction. Further experimental work would be needed to resolve this temperature dependence. The LCV technique may also prove to be useful to evaluate the performance of environmental remediation projects involving the injection of $\mathrm{H}_{2} \mathrm{O}_{2}$ into contaminated waters. Many groundwaters contain dissolved iron, which could make it difficult to determine the residual $\mathrm{H}_{2} \mathrm{O}_{2}$ concentration. With the LCV techniques samples can be treated with ETDA and preserved for latter analysis.

\section{CONCLUSION}

This study demonstrates a reliable and efficient method for quantifying $\mathrm{H}_{2} \mathrm{O}_{2}$ from iron-containing mineral slurries and waste by use of separate calibration curves to account for $p \mathrm{H}$ and iron concentrations. The stability of the colored $\mathrm{CV}^{+}$ makes this method suitable for the field or when immediate access to a spectrophotometer is not possible. Relative to the concentration of $\mathrm{H}_{2} \mathrm{O}_{2}$ consumed, the reported ${ }^{25}$ high molar absorptivity of $75000 \mathrm{M}^{-1} \mathrm{~cm}^{-1}$ for $\mathrm{CV}^{+}$makes it possible to determine $\mathrm{H}_{2} \mathrm{O}_{2}$ at sub- $\mu \mathrm{M}$ concentration levels. In ironcontaining systems at low $p \mathrm{H}$, hydrogen peroxide reacts to form ${ }^{\circ} \mathrm{OH}$. Under those conditions, the presence of $\mathrm{H}_{2} \mathrm{O}_{2}$ as an intermediate to $\mathrm{OH}$ formation would be extremely difficult to detect. The LCV technique as outlined provides a relatively simple method to demonstrate the involvement of $\mathrm{H}_{2} \mathrm{O}_{2}$ under those conditions.

\section{ACKNOWLEDGMENTS}

This work was funded by the Department of Energy through grants to D.R.S. and M.A.S., Basic Energy Sciences Grant Nos. DEFG029ER14644 and DEFG0296ER14633, respectively. The Center for Environmental Molecular Science (NSF CHE 0221934) facilitated the contribution of A.P. to this project. C.C. would like to acknowledge support from a National Defence Science and Engineering Fellowship.

${ }^{1}$ J. D. Willey, R. J. Kieber, and R. D. Lancaster, J. Atmos. Chem. 25, 149 (1996).

${ }^{2}$ B. C. Faust and J. M. Allen, Environ. Sci. Technol. 27, 1221 (1993).

${ }^{3}$ P. J. Hakkinen, A. M. Anesio, and W. Graneli, Can. J. Fish. Aquat. Sci. 61, 1520 (2004)

${ }^{4}$ L. J. A. Gerringa, M. J. A. Rijkenberg, K. R. Timmermans, and A. G. J. Buma, Netherlands J. Sea Res. 51, 3 (2004).

${ }^{5}$ M. Amme et al., Environ. Sci. Technol. 39, 221 (2005).

${ }^{6}$ F. Clarens et al., Environ. Sci. Technol. 38, 6656 (2004).

${ }^{7}$ E. Ahlberg and A. E. Broo, Int. J. Min. Process. 47, 49 (1996).

${ }^{8}$ J. M. Allen, S. Lucas, and S. K. Allen, Envir. Toxicol. Chem. 15, 107 (1996).

${ }^{9}$ M. J. Borda, A. R. Elsetinow, D. R. Strongin, and M. A. Schoonen, Croat. Chem. Acta 67, 935 (2003).

${ }^{10}$ W. Stumm and J. J. Morgan, Aquatic Chemistry: Chemical Equilibria and Rates in Natural Waters, 3rd ed. (Wiley-Interscience, New York, 1995), p. 1022.

${ }^{11}$ P. Vaughan and N. Blough, Environ. Sci. Technol. 32, 2947 (1998).

${ }^{12}$ P. R. Gogate and A. B. Pandit, Adv. Environ. Res. 8, 501 (2004).

${ }^{13}$ M. Arienzo, Chemosphere 39, 1629 (1999).

${ }^{14}$ W. Dröge, Physiol. Rev. 82, 47 (2002).

${ }^{15}$ J. Nordberg and E. S. J. Arnér, Free Radic Biol. Med. 31, 1287 (2001).

${ }^{16}$ T. Finkel and N. J. Holbrook, Nature (London) 408, 239 (2000).

${ }^{17}$ W. A. Pryor, Annu. Rev. Physiol. 48, 657 (1986).

${ }^{18}$ C. P. Lebel, H. Ischiropoulos, and S. C. Bondy, Chem. Res. Toxicol. 5, 227 (1992)

${ }^{19}$ C. C. Winterbourn, Free Radic Biol. Med. 3, 33 (1987).

${ }^{20}$ K. Makino, T. Hagiwara, A. Hagi, M. Nishi, and A. Murakami, Biochem. Biophys. Res. Commun. 172, 1073 (1990).

${ }^{21}$ A. G. Hildebrandt and I. Roots, Arch. Biochem. Biophys. 171, 385 (1975).

${ }^{22}$ K. Kosaka, H. Yamada, S. Matsui, S. Echigo, and K. Shishida, Environ. Sci. Technol. 32, 3821 (1998).

${ }^{23}$ T. Holm, G. George, and M. Barcelona, Anal. Chem. 59, 582 (1987).

${ }^{24}$ C. Rota, C. F. Chignell, and R. P. Mason, Free Radic Biol. Med. 27, 873 (1999).

${ }^{25}$ H. A. Mottola, B. E. Simpson, and G. Gorin, Anal. Chem. 42, 410 (1970).

${ }^{26}$ L. S. Zhang and G. T. F. Wong, Talanta 41, 2137 (1994).

${ }^{27}$ S. J. Gregg and K. S. W. Sing, Adsorption, Surface Area and Porosity (Academic, London, 1982).

${ }^{28}$ M. Borda, A. Elsetinow, M. Schoonen, and D. Strongin, Astrobiology 1, 283 (2001)

${ }^{29}$ C. A. Cohn, M. J. Borda, and M. A. Schoonen, Earth Planet. Sci. Lett. 225, 271 (2004).

${ }^{30}$ C. L. Wilson et al., Environ. Sci. Technol. 34, 2655 (2000). 